\title{
Think Bubbles and Socrates: Teaching Critical Thinking to Millennials in Public Relations Classes
}

\author{
Rebecca J. Tallent", Justin J. Barnes \\ School of Journalism and Mass Media, University of Idaho, USA
}

Copyright $(\mathcal{C} 2015$ by authors, all rights reserved. Authors agree that this article remains permanently open access under the terms of the Creative Commons Attribution License 4.0 International License

\begin{abstract}
Critical thinking skills are crucial in the public relations profession, but teaching these skills to the Millennial Generation is vastly different from previous generations. How can a professor get past No Child Left Behind's dependence on test review guides and "everybody wins" in getting students to think for themselves? Using the Socratic method along with thinking tools/exercises, students can learn how to devise their own solutions using quality critical and creative thinking.
\end{abstract}

Keywords Critical Thinking, Socratic Method, Maieutic Method

\section{Introduction}

Whether students plan to enter corporate, government or not-for-profit public relations, quality critical thinking skills are required for all professionals. It does not matter if they want to be an internal corporate communications specialist, a lobbyist, development officer or investor relations specialist, understanding the need to independently and quickly analyze situations is critical to the profession.

But how to teach critical thinking, or CT, to students born between 1981 and 2000 who have been spoon-fed the "everybody wins" philosophy (1) or prepare these same students who have been taught the test rather than independent thinking skills through No Child Left Behind programs? The authors acknowledge not every person in the Millennial generation has the following attributes; and that the experiences are generalized to college students who are normally from middle to upper-middle class families. The following describes generational similarities.

Pompper (2) defines Millennials as Generation $M$ and EchoBoomers, the offspring of Baby Boom and Generation $\mathrm{X}$ parents. These are, Pompper (2) said, a diverse group of multitaskers and early technology adapters who appreciate group work and structured activities. These are students Todd (3) described as: entitled, self-indulgent, short sighted and lacking a work ethic. The attributes Todd (3) recounts of Millennials in the workplace do not immediately lend themselves to the idea of independent, quick critical thinking required in the public relations profession. In addition, Bergman, Fearrington, Davenport and Bergman (4) outright call Millennials a narcissistic generation who hold an inflated view of themselves, believing they are special or unique, expecting special treatment while owing nothing in return. This opposes how most public relations professionals view themselves, which is normally one of intellectually curious individuals with good problem-solving abilities who can work as team players in a service industry with a competitive yet "can do" attitude to service the needs of the client (5, p 40).

Some researchers $(6,7)$ have placed the lack of critical thinking skills exhibited by the Millennial generation on the shoulders of the parents, who have managed all their children's needs throughout their lives. Some of these parents have gone beyond helping a child to research a prospective employer, they have submitted resumes for the children, made interview arrangements, and called managers for feedback after an interview (6). Anecdotally, professors have referred to over-protective parents as "helicopter parents" because they hover around the child, even going so far as to purchase a new family home in the college or university community so they can stay with their child through college, paying close attention to what happens to their child in post-secondary environment. Additionally, some faculty tell anecdotes of "snow-plow parents" or "bulldozer parents," so-called because they will push for their child rather than pushing the child to achieve on their own. Other terms used by faculty and administrators include cosseting parents and lawnmower parenting. Such protectiveness prevents the Millennial from making their own decisions or learning how to use appropriate critical thinking skills. This type of parenting also prevents the child/young adult from developing motivational skills, an offshoot of learning theory, which Weiler (7) identified as a primal element to driving the need to develop critical thinking skills. Weiler (7, p. 47) said "The issue of critical thinking cannot be separated from how students view their information universe." This impacts how public relations students collect and use information in the public relations work place. 
The Foundation for Critical Thinking (8) defines critical thinking as: “ $\ldots$ the intellectually disciplined process of actively and skillfully conceptualizing, applying, analyzing, synthesizing, and/or evaluating information gathered from, or generated by, observation, experience, reflection, reasoning, or communication, as a guide to belief and action. In its exemplary form, it is based on universal intellectual values that transcend subject matter divisions: clarity, accuracy, precision, consistency, relevance, sound evidence, good reasons, depth, breadth, and fairness..."

Karen-Leigh Spicer (9) said students must develop quality critical thinking skills because public relations professionals must possess quality communications skills and the social sensitivity necessary to help organizations adapt to their environments. "Critical thing is adopting an attitude that is open to both sides of an argument. It is the capacity to distinguish beliefs from knowledge, and fact from judgement. The PR student should first define the problem, examine the evidence and analyze the assumptions underlying the evidence," Spicer said (9, p. 2-3). By doing this, she said, students increase their understanding of PR and can apply this skill to help organizations change with the environment.

Guth and Marsh (10, p. 296) maintain critical thinking is a core concept of public relations that requires the practitioner to be able to conduct "goal-oriented, objective, comprehensive, systematic mental exploration of a subject of a particular problem or a particular public, for example." Many practitioners rely on Plato's critical thinking system, Platonic dialectic, which can be used internally or within a group (10). Key to this system is the ability to specify a goal, define the terms, analyze, synthesize, evaluate and summarize the information or situation, in addition to being able to accept ambiguity as a possible part of the equation. By playing off what VanMeter, Grisaffe, Chonko and Roberts (11) called the Millennial or Gen-Y attributes of high idealism/high relativism, which has them as a group tending toward situationalism, but stymied by the addition of ambiguity, public relations professors can develop methods of actively promoting CT skills in a way that can incorporate analysis into their everyday thinking, making them ready for the workplace and managers who depend on public relations professionals to be clear-sighted in their observations of breaking news or issues management.

\section{Why Critical Thinking is Important}

Teaching critical thinking is a key element for communications courses, especially journalism and public relations, so there is a significant amount of information available. One of the now-standards is Melissa Fine's "Habits of the Mind" (12), although she does focus on all classrooms and the political debate over classrooms in general. Still, Fine (12) provides solid groundwork for teaching CT, which is essential for successful public relations practitioners. In her 1995 work, Fine (12) said while here has been a struggle over common core classroom values (especially moral education vs. character education), understanding meaning is still crucial and that takes CT skills.

Critical thinking skills are the number two demanded skills set for PR practitioners, just behind writing skills (13). In a 2008 study of PR counselors and executives, McClenegham (13) said only two variables were statistically significant between the counselors and management executives: critical thinking and judgment/decision making. "No doubt critical thinking must be done by both PR executives and independent counselors. They would not be in leadership roles and remain in the business if they could not critically think for a living," McClenegham (13, p 17) said. He further noted the judgment and decision making skills were often done under stressful conditions, but these skills also require quality critical thinking.

McClenegham's study focused on older practitioners. A 2014 study by Todd (3) concluded, among other issues, that Millennials are not good at CT as they exit college. After surveying both Millennial-age employees and their employers, Todd (3) said there is a discrepancy between employees and employers in the perception of how well Millennial-age employees use their critical thinking skills: the Millennials arguing they have excellent professional critical thinking skills while the employers, on the whole, disagree. As Todd (3, p. 794) further explained:

The supervisors did not find the Millennials' job performance as proficient. Twenty-three percent of the supervisors commented that educators should teach students more developed critical thinking skills. Millennial respondents rated their critical thinking above average, and only $12 \%$ of Millennials suggested educators focus on enhancing this skill.

Other critical thinking experts, such as Michael Michalko (14), recommend a variety of tools, such as the SCAMPER (substitute, combine, adapt, modify/magnify, put to other uses, eliminate, reverse/re-arrange) way of channeling problem issues; the Circle of Opportunity method of brainstorming in which problems are divided into 12 parts and sections are analyzed in random fashion according to a roll of dice; and visualization techniques in which problems are removed from the issue and mentally transported to another location so they can be analyzed on their own. Michalko (14) claims these can be used by any age group and are not Millennial-specific.

Speaking directly to the higher education classroom, Bracy, Bevill \& Roach (1) said the Millennial generation needs to be taught quality CT skills, but professors need different delivery methods. This involves everything from varying the types and lengths of assignments to keeping a casual classroom. But, how does this play into teaching or developing pedagogies for CT?

\section{Can Existing Pedagogies Mesh?}

Dr. Lance Grigg (15) posits that CT pedagogies can mesh, 
and that the styles should challenge students through problem solving, problem-posing, developing sound arguments and simply making good decisions. Grigg (15) believes there is no magic bullet in the pedagogy style instructors choose, but in turn, he feels that effective CT pedagogy should be about developing strategies that deepen the quality of students' capacities for sound reasoning across the curriculum and outside the box thinking. After explicit instruction of classroom content, the students need to be asked to compose argument maps, explain the reasoning used in constructing those maps, and defend their positions to peers and instructors. Grigg (15) believes if the pedagogy is administered effectively, students will produce well-reasoned arguments and positions supporting their beliefs and findings. A few pedagogical methods that have been effective in this challenge are the Socratic and Social Constructivist approach in the classroom.

The Socratic style of instruction is a form of Socratic instruction style that involves discussions, questioning, and analyzing (16). This method encourages students to analyze their own beliefs as well as the beliefs of others and is a student centered learning method (17). The goal is to create discussion that draws on the students' skills of reading, writing, speaking, and listening, and which should sharpen their ability to think clearly, critically, and reflectively (16, p. 30 ). Essentially, the method encourages students "to think for themselves, to respond to and ask important questions, to pursue arguments, to defend a point of view, to understand antagonistic views, and to weigh alternatives" (16, p. 30).

Another form often used to generate critical thinking is a social constructivist style of the pedagogy. Social constructivist pedagogy emphasizes and applies various classroom formats that are student centered to guide the content. Social constructivism views each learner as a unique individual with unique backgrounds and needs that guide his or her learning process (18). The learner is also seen as complex and multidimensional through their experiences. Social constructivism acknowledges the uniqueness and complexity of the learner, and also encourages, utilizes and rewards it as an integral part of the learning process (18). As part of his pedagogical style, students discuss content from classroom text through group work, discussion questions, and reflective writings. In addition, the instructor should permit students to drive discussion while facilitating the pace. Expectations from this pedagogical style are that students will develop knowledge through experience and application of content from a variety of settings (19).

The classroom examples provided in the next section of this work show that these pedagogies can mesh - in fact, do mesh well - and this allows the instructor to build off each style/concept as the students' progress through a public relations program.

\section{Teaching Critical Thinking to Gen-Y}

Unlike the idealism espoused by Jean Piaget with his experimentation on how learning happens (20), Millennials have not been raised left to their own exploration (1). They have been told what to learn, how to learn it and what is expected for them to know on the test. This pedagogical format does not encourage critical thinking or developing the ability to think for her or his self. As a result, students come to college without the basics of CT.

If one embraces the Socratic principle - The unexamined life is not worth living - this may be an appropriate approach for the Millennial generation, especially since this generation, overall, has a tendency toward idealism and visual learning. Stoll and Beller (21) state the Maieutic Socratic teaching methodology is a holistic learning philosophy in which the student is the focus and the interchange of ideas and reasoning is the social environment. Stoll and Beller (21) claim that this method needs to make students move from passive learners to active "reasoners." In addition, students should be challenged to read, think, and ponder as they actively argue, question, and discuss, all aspects of important social and personal issues in the subject content.

With both student and teacher focusing on interactive discussion through use of active listening skills and empathetic argumentation, participants may come to appreciate divergent points of view and in the process improve their own critical thinking and reasoning skills. The difficulty in adapting to this type of methodology is the ingrained teaching styles that emphasize content as the only focus. Essentially this approach is a radical departure from the lecture, information-centered approach, which is often practiced in university classrooms, where the instructor is the center or focus of the learning experience (17).

For this pedagogical method to succeed, the instructor must be willing to facilitate discussion and be open to multiple dialogues, even criticism from the students. This is often a risk because students are often encouraged to state their own opinions, which can lead to a challenge of the instructor or allow the students to demonstrate the instructor's opinion is wrong (21). Because this is a vital component to the critical thinking process, it is crucial the instructor be open to taking the risk of engaging in dialogue with the class. In this role, the instructor must be open to trying new and innovative approaches that may or may not be successful. The key here is for the instructor or professor to be willing to try.

At the University of Idaho, there are CT techniques used in public relations classes that seem to have a positive impact on Millennials adopting critical thinking techniques.

In the sophomore level Introduction to Public Relations, the professor begins each class with what is happening in news, showing how the news relates to many public relations issues. This eases the students into the concepts of CT without the students worrying if they are doing the assignment "right" or not - it allows each student to use their own analysis of the day's news to answer questions. Early in the semester, the professor begins prodding the students to think behind the headlines - how does this make people or an organization look? The professor then begins to expand the questions about impact and extended issues. 
For example, a news story about the National Oceanographic and Atmospheric Administration research showing increases in air and ocean temperatures from year-to-year, the first question would be: Why is this news? Follow-up questions would include:

- How will this impact business?

- What types of businesses may be impacted?

- How about sports and entertainment venues, what might happen?

- Might this eventually impact how much money people give to charities?

- What about changes around the home? The price of food?

In this case, the students responded by saying they thought the initial businesses that might be affected were any groups who need to deal with weather, such as NOAA, and they brought up travel businesses such as airlines. More prodding got them to think about concerns dependent on weather, and someone said fishing. That response brought an avalanche of responses, such as farmers, ranchers, sustainability businesses, which quickly jumped to the cost of food in local stores. Other issues raised by the students included transportation costs increasing because, maybe, some smaller agribusiness concerns might go out of business. That quickly jumped to concern about water in general, evaporation of certain systems and an increased dependency on local aquifers, and how that would impact a variety of business types.

Asking about personal life, the students immediately said warmer weather would impact skiing and winter sports, but they said they could also see issues with other sports as well. Going back to the idea of a stressed agribusiness industry, they students began to talk about increases in food prices beyond the grocery store: also at farmer's markets, restaurants and entertainment venues such as movies. Very quickly, they began to see a variety of problems which could be associated with the NOAA report of increased temperatures and how the impact was not necessarily limited to one specific area. They also began talking about possible alternatives and solutions, although they admitted they had no real abilities to do anything on that day.

Another way to get younger college students involved with clear CT is mind mapping, or as Michalko (14) calls it: Think bubbles. The mind mapping/think bubbles approach to CT could also be considered an extension of the Socratic approach, one that draws upon student inclination toward visual knowledge and augmentation. As the semester progresses, moving into think bubbles helps students develop their CT skills is a non-threatening, and often fun, manner.

"Think bubbles" is a graphic technique much like writing out ideas on whiteboards or pieces of paper, except it uses the following step-by-step technique (14) (see appendix):

- Organization, in which each person organizes the material in their own way, as their mind works. Using a large board or paper, group related ideas together, using arrows to denote special relationships.
The visual nature of mapping makes it easier for many people to see the connections.

- Reduce all ideas to key words, getting to the essence of the idea.

- Association to make connections, links and relationships between what seem to be disparate, unconnected ideas. This opens the door to many new ideas.

- Clustering, or bringing the ideas together, this allows students to look at an idea more critically as more information is given to the brain.

- Conscious involvement, or making sure the map requires the participants concentrate on the challenge by grouping and re-grouping the think bubbles.

First-year public relations students can use this technique as they map out a problem for a class client. At the University of Idaho, each class has between 7 and 10 local businesses or not-for-profit organizations for whom the students create a media kit as a team project. The think bubbles help the team members get to know each other, and how they think, and the various ways people think as they carefully consider the problems and how to craft an appropriate kit that meets the needs of the individual clients.

In an advanced campaign course, students are tasked with generating a budget regarding the cost for implementing an integrated marketing communication plan. The idea behind generating ambiguity is putting students in the role as a discoverer. The budget assignment objective is for students to research the cost of production based on time, resources and services required. Instead of informing the students to keep their plan within a specific budget number, they are required to choose a number, and defend their number and what it will be able to accomplish for the client. The notion is that this assignment will compel students to critically think about the multiple layers involved an integrated marketing communication plan, and what they can realistically accomplish with the available resources.

In a senior public relations campaign design class, students need to use more complex methods. While also employing think bubbles, the professor adds more techniques so students can continue developing CT skills, such as when the students were considering the variables needed for research. The professor offered as an example the president's State of the Union address, which had been given the previous week. The students named several of the areas touched upon in the speech, and then began to consider what types of research the staff conducted prior to the speech being given.

Students immediately began to rely on research techniques mentioned in the textbook, including focus groups, interviews and content analysis. The professor nudged them through questioning about other forms of research they might conduct. These questions included:

- But what if the information they really need can't be teased from a focus group or content analysis? What else can be used?

- What are some of the everyday tools people use? 
How can these be used for research? (Think beyond the "research" label.)

- What are some of the questions that go along with these issues? How can these questions be translated into a research tool?

Eventually, the class members began to think beyond the text and give answers such as: reports from businesses involved, public opinion polling, advice from counselors (government, corporations and think tanks), situational analysis, statistical reports, economic surveys, critical analysis of economic trends, and paying attention to letters, email and social media on the various topics. As the class members began to expand their thought process, the answers of different types of research began to spill faster and faster with only a few ideas rejected by the class. The result was students who saw there are more types of research available than the traditional, sometimes expensive, formats; that they, too, can use research formats for their own immediate projects.

One technique many PR professionals use when planning a campaign or project is to visualize: mentally walk through the project to spot potential problems, something both the Socratic and Maieutic methods encourage as a logical way of "seeing" critical thinking. Another technique encouraged with the senior class is Michalko's (14) "Not Kansas" exercises, in which participants think about a problem, then relax and visualize the problem as an imagining process. Then they ask their unconscious for an answer to the challenge, writing down the symbol their unconscious gives them. They then take a guided imagery tour and accept whatever messages emerge from the mental tour. Using their imagination, the participants then make the images as clear and vivid as possible, recording or drawing the answers. If the participant has conflicting images, he or she needs to conjure up other images. The final step is to look for patterns, qualities, relationships and clues within the images that can lead a person to the answer he or she seeks. In short, this is close to mentally walking through a PR campaign, making sure all contingencies are examined and there are answers/solutions prepared. "Not Kansas" (14) allows teams to mentally walk through the various aspects of the comprehensive campaign they are creating for a real client, allowing them to see if the plan can work as they envision, or if there are conflicts inherent because it was created by a team of three or four people.

These are just three of the additional techniques offer by Michalko (14) used by the PR program. The point here is the students are offered the opportunity to expand their CT horizons using methods that are non-threatening, especially to their predisposition of "everybody wins" while branching them away from the idea of only learning for a test.

\section{Discussion}

Does all this work? Yes, but it is important to regularly task students with reflective writing assignments regarding choices (22). The reflective writings should ask students to engage in a dialogue supporting their beliefs and actions, and challenge them to be responsible for supporting their beliefs and actions in both specific and general situations. Throughout the semester, the writing process should occur regularly, and it is imperative that students learn how to articulate a writing narrative that draws from reading, speaking, and listening to course content. In essence, the writing assignments should sharpen their ability to think clearly, critically, and reflectively (16, p. 30). Fundamentally, reflective writing allows students to respond to and ask important questions, to pursue arguments, to defend a point of view, to accept antagonistic views, and to weigh possible alternatives.

Anecdotal evidence shows the process does have an impact. Student evaluations for the introductory course often discuss how much they liked learning about PR through the news, especially how people perceive an organization as it appears in media reports. In later classes, the same students often express disappointment that each class does not start with a discussion of news, frequently saying, "That was my favorite part of the class."

Older students respond less often in course evaluations to the CT exercises, but do comment they learned new ways of thinking about a subject or organization. Some say processes such as think bubbles get them to question more about a situation, and other students say they liked the idea of thinking through an event or situation to see where there could be improvements or possible issues. Graduates sometimes connect with the faculty to relate stories of how they used situations in class to help them deal with a professional problem, and explain the use of the Socratic method, think bubbles or not Kansas. Other anecdotal evidence comes from other professors who said they are impressed with the way some PR students think their way through issues; although one professor has complained although they would like to follow suite, they do not have the time to look at news at the start of every class, as requested by some PR majors. What is important is the students are talking - and thinking - about news and situations presented in class. It is incumbent upon them to make decisions about the situations, complete with ambiguities. For many Gen-Y students, it is the first time in their lives they have been forced to make the own decisions based on data presented and analyzed by them, not given the answers by the instructor.

\section{Conclusions}

Professors working with college students of the Millennial generation understand this group does think differently than other, previous generations, thanks to No Child Left Behind, the "everyone wins" philosophy under which they have been raised and parents who remain exceptionally protective of their children. However, teaching critical thinking to this group is not impossible; it just requires a different tack, one that requires a way of maintaining their attention. 
Using the "ripped from the headlines" approach actually does double-duty in that it gets students to pay attention to the news and think through what the news means to a company, organization or client in relation to their job as a PR person. This method stands an excellent chance of maintaining interest, especially if the students begin to view it as pop culture, what is happening now, so it has relevance in their lives. Using the Socratic method along with the news not only challenges students to determine their own answers, it also encourages them to explore the various subjects in more detail and arrive at conclusions which may be original and unique. This also gives Millennial students the opportunity, many for the first time in their lives, to begin their own exploration of a topic without someone giving them a "right" answer. They can explore on their own or in a small group and learn how to grapple with the problem of ambiguity, a problem they will fact in their professional life multiple times. This type of empowerment can also lead to developing CT skills, which is a topic for another paper.

In some classrooms, the Maieutic Socratic Method can be employed, openly encouraging students to make the move from passive learners to active reasoners, which should be the goal of all PR professors and professionals. Using this method, students can be challenged to become quality listeners who can debate with empathetic argumentation, showing themselves to be fully engaged in the process. This requires freedom within the classroom for the students to bounce ideas and defend their own thinking process, and the professor should be aware the students can develop theories and conclusions that are contrary to the opinions of the faculty. As educators, faculty should encourage this type of thinking, especially if the student can clearly and logically define her or his conclusions.

While encouraging both the Socratic method and the "ripped from the headlines" approach can be a risk for some classrooms, it allows the students the freedom to explore. By using some confines, such as offered by Michalko (14), the students can have the familiar feeling of restrictions while unleashing both their critical and creative thinking powers, many for the first time in their young lives. This can lead to quality critical thinking and a successful career as a public relations practitioner.

\section{Appendix}

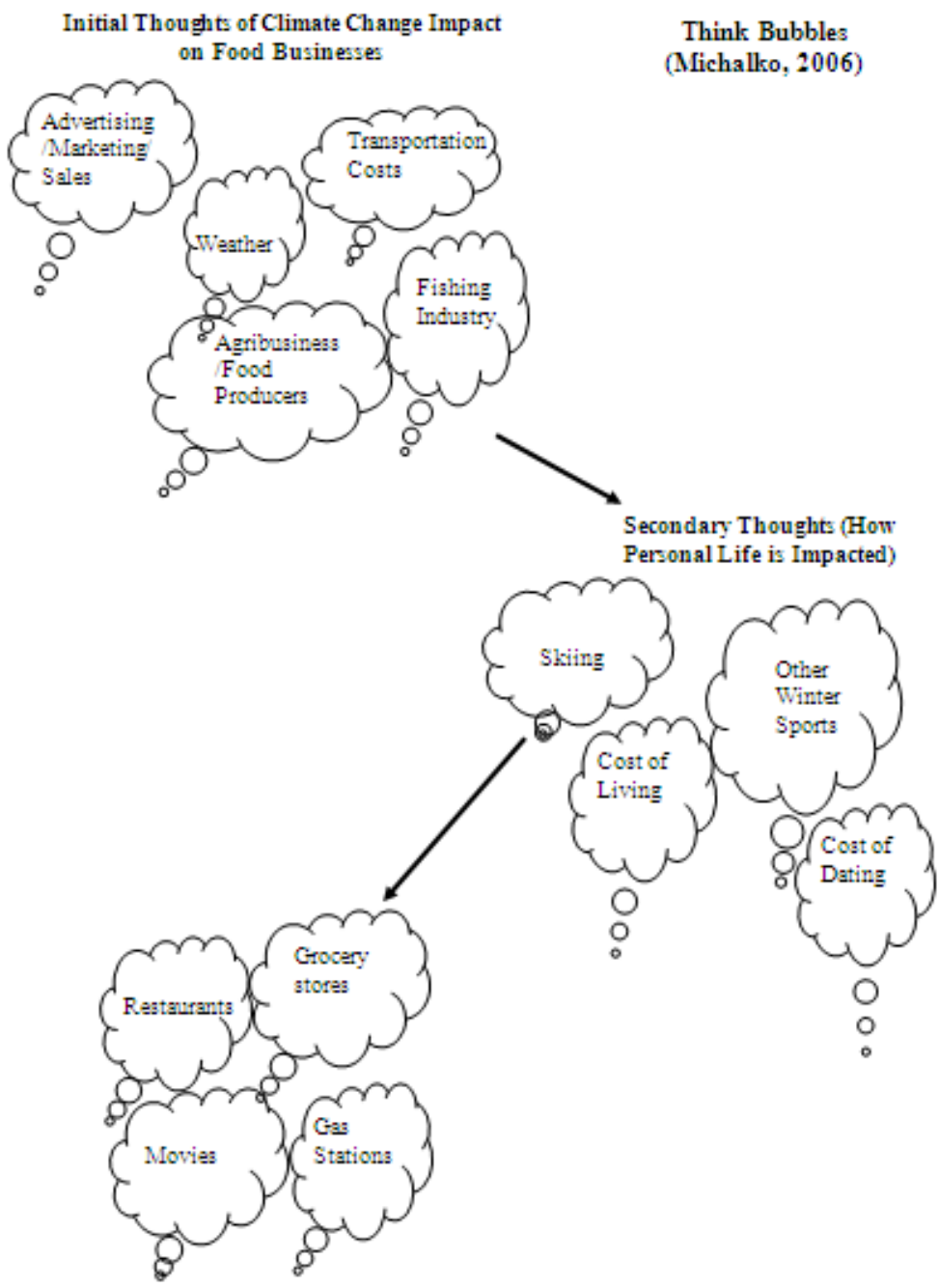




\section{REFERENCES}

[1] Bracy, C, Bevill, C, Roach, TD. The Millennial generation: Recommendations for overcoming teaching challenges. Proceedings of the Allied Academics International Conference, Academy of Educational Leadership. 2010.

[2] Pompper, D. Cheap labor speaks: PR adjuncts on pedagogy and preparing Millennials for careers. Public Relat Rev. 2011 Dec; 37 (5): 456-465.

[3] Todd, V. Public relations supervisors and Millennial entry-level practitioners rate entry-level job skills and professional characteristics. Public Relat Rev. 2014, Dec; 40 (5) 789-797.

[4] Bergman, SM, Fearrington, ME, Davenport, SW, Bergman, JZ. Millennials, narcissism and social networking: What narcissists do on social networking sites and why. Pers Individ Dif. 2011; 50 (5) 706-711.

[5] Broom, GM, Sha, B-L. Cutlip \& Center's effective public relations. $11^{\text {th }}$ ed. Boston, MA: Pearson Education, Inc.; 2013.

[6] Harris, B. Why does Gen Y lack critical thinking skills? [Internet]. Available from Critical Thinkers at http://www.critical-thinkers.com/2010/07/why-does-gen-y-la ck-critical-thinking-skills/

[7] Weiler, A. Information-seeking behavior in Generation Y students: Motivation, critical thinking and learning theory. Journal of Academic Librarianship 2004; 31 (1) 46-53.

[8] Scriven, M, Paul, R. Critical thinking defined [internet]. Presented at the 8th Annual International Conference on Critical Thinking and Education Reform, 1987, summer. Available from The Foundation for Critical Thinking http://www.criticalthinking.org/pages/critical-thinking-wher e-to-begin/796

[9] Spicer, K-L. The application of critical thinking skills in the public relations curriculum. [Internet]. Presented at the Annual Meeting of the Speech Communication Association, Oct. 31-Nov. 3, 1991. Available from the Institute of

Education Sciences http://eric.ed.gov/?id=ED343190.

[10] Guth, DW, Marsh, C. Public relations: A values-driven approach. $5^{\text {th }}$ ed. Boston, MA: Allyn \& Bacon/Pearson; 2012.

[11] VanMeter, RA, Grasiffe, GB, Chonko, LB, Roberts, JA. Generation Y's ethical ideology and its potential workplace implications. J Bus Ethics. 2013; 117 (1) 93-109.

[12] Fine, M. Habits of mind: Struggling over values in America's classrooms. San Francisco, CA: Jossey-Bass Publishers; 1995.

[13] McClenegham, JS. The PR counselor vs. PR executive: What skill sets divide them? Public Relat Q, 2009; 52 (4) 15-17.

[14] Michalko, M. Thinkertoys: A handbook of creative thinking techniques. 2nd ed. Berkeley, CA: 10 Speed Press; 2006.

[15] Grigg, L. Critical thinking pedagogy in the classroom. [Web log comment]. 2012. Available from:

http://www.uleth.ca/education/story/4082

[16] Adler, MJ. The paideia proposal: An educational manifesto. New York: Macmillan Publishing Company; 1982.

[17] Gill, J. Learning to learn: Toward a philosophy of education. New York: Prometheus Books; 1993.

[18] Wertsch, JV. Vygotsky and the formation of the mind. Cambridge, MA: Harvard University Press; 1997.

[19] Meyer, SR, Marsick, VJ, King, KP, Lawler, PA. Professional development in corporate training. New Directions for Adult \& Continuing Education, 2003; 2003 (98) 75-82.

[20] Erneling, CE. The importance of Jean Piaget. Philos Soc Sci, 2014; 44 (4) 522-535.

[21] Stoll, SK, Beller, JM. Can character be measured? J Health Edu, 1998; 69 (1), 19-23.

[22] McNeel, S. College teaching and student development. In Rest, J, Narvaez, D, editors. Moral development and the professions: Psychology and applied ethics. Hillsdale, N.J.: Lawrence J. Erlbaum Associates; 1994; (26-47). 